\title{
Beyond equivalence: prisoners' right to health
}

\author{
Tim Exworthy, ${ }^{1,2}$ Simon Wilson, ${ }^{1,2}$ Andrew Forrester ${ }^{2,3}$
}

The Psychiatrist (2011), 35, 201-202, doi: 10.1192/pb.bp.110.033084

${ }^{1}$ Memorial Hospital, Oxleas NHS Foundation Trust, London; ${ }^{2}$ Institute of Psychiatry, King's College London; ${ }^{3}$ Healthcare Department, HMP Brixton, London, UK

Correspondence to Tim Exworthy (tim.exworthy@kcl.ac.uk)

First received 14 Oct 2010, accepted 1 Mar 2011
Summary Prisons have high levels of psychiatric morbidity and function as mental illness recognition centres. Their healthcare wings are not hospitals and timely transfers to hospital are often unavailable. The United Nations' right to the highest attainable standard of health is assessed according to whether healthcare services are available, accessible, acceptable and of good quality (AAAQ). It is proposed that the AAAQ framework goes beyond the principle of equivalence of care and provides a more sophisticated measure for exploring prison healthcare.

Declaration of interest None.
There are more mentally disordered people in prisons than ever before. In the UK, Lord Bradley has re-affirmed the government's longstanding approach of diversion, ${ }^{1}$ with earlier intervention and prevention as possible future solutions. The principle of equivalence of care $^{2}-$ that prisoners are entitled to the same standard of healthcare as they would have were they not in prison - is meant to underpin the provision of prison healthcare services. Equivalence has been useful in identifying prison healthcare problems and driving systemic improvements. ${ }^{3}$ However, prisons are not equivalent to the community in a number of important areas. They are complex institutions with their own rules. Although illness in prisons is excessive, ${ }^{4}$ prison healthcare wings are not hospitals ${ }^{5}$ and treatment under the Mental Health Act is not possible. ${ }^{6}$ Prisons also function as mental illness recognition centres, ${ }^{7}$ although timely hospital treatment is often unavailable. ${ }^{8}$ To continue to enforce a measure of community equivalence within prison healthcare would be to impose standardisation of the inherently dissimilar, and cause the latter to fail.

\section{AAAQ framework}

The 1966 United Nations (UN) International Covenant on Economic, Social and Cultural Rights has detailed a right to the highest attainable standard of health for every person ${ }^{9}$ and has suggested the AAAQ framework - that healthcare should be available, accessible, acceptable, and of good quality $^{10}$ - as a paradigm to assessing the progressive realisation of that right.

1 Availability: is the provision of healthcare services sufficiently available through the prison estate, and operated by properly trained health professionals, to protect prisoners' health?

2 Accessibility: are services physically and geographically available within a good timescale (including hospital care for those who require it); are they economically accessible to users; do they offer access to relevant information and choice; and are they accessible to all, especially the most marginalised in society, without discrimination?

3 Acceptability: do the services meet a good standard of cultural and ethical acceptability, including having individualised care?

4 Good quality: is the environment (including minimal standards for accommodation, nutrition and sanitation) appropriate; is the service clinically safe and effective; is medical equipment of a suitable standard; are modern and appropriate medicines provided?

\section{Four tests of a healthy prison}

The UN model, which contains the concept of equivalence, resonates with Her Majesty's Inspectorate of Prisons' four tests of a healthy prison ${ }^{11}$ - safety, respect, purposeful activity, resettlement - and could be similarly measured and publicly reported. We suggest that this would offer a more sophisticated measure for exploring prison healthcare, by more honestly describing the limitations and more accurately producing focused change within custodial settings.

How might this work in practice? We envisage specialist healthcare incorporation of each test into the existing prisons inspectorate, with transparent national reporting structures. Each aspect of the test could then be measured according to its constituent parts. A typical local prison in England and Wales will almost certainly have available services (including fully trained primary and secondary care staff), although it is unlikely to be sufficiently funded or of sufficient quantity. ${ }^{12}$ It will operate a waiting list for assessment and treatment, as in the community, but could well exceed community expectations by delivering triaged care quickly. It is likely to offer patchy 
information, with limited choice and individualisation, but it will be free to all users irrespective of economic disadvantage. It is unlikely to offer an appropriate clinical environment, as many prisons were built in the 19th century, with limited adaptation possible for modern health and safety requirements (such as removal of ligature points). However, appropriate equipment, food and sanitation are likely to be available. Other measures such as non-discrimination, cultural and ethical acceptability, and overall clinical effectiveness and safety, would require further in-depth local examination. This would bring an imperative regarding locally derived clinical governance standards, which are presently patchily available.

European human rights jurisprudence has determined the level of the floor in terms of standards and conditions of psychiatric care in prisons so as to avoid violations of Article 3 (relating to inhuman and degrading treatment) ${ }^{13}$ and Article 5 (relating to inappropriate detention of the mentally disordered $)^{14}$ of the European Convention on Human Rights. Focusing on the AAAQ regime offers the opportunity to raise the height of the roof.

\section{About the authors}

Tim Exworthy and Simon Wilson are both consultant forensic psychiatrists, Memorial Hospital, Oxleas NHS Foundation Trust, and visiting senior lecturers in forensic psychiatry, Institute of Psychiatry, King's College London. Andrew Forrester is consultant forensic psychiatrist, Healthcare Department, HMP Brixton, London, and visiting senior lecturer in forensic psychiatry, Institute of Psychiatry, London.

\section{References}

1 Lord Bradley. The Bradley Report. Lord Bradley's Review of People with Mental Health Problems or Learning Disabilities in the Criminal Justice System. Department of Health, 2009.
2 HM Prison Service, NHS Executive. The Future Organisation of Prison Health Care. Report by the Joint Prison Service and National Health Service Executive Working Group. Department of Health, 1999.

3 Wilson S. The principle of equivalence and the future of mental health care in prisons. Br J Psychiatry 2004; 184: 5-7.

4 Fazel S, Danesh J. Serious mental disorder in 23,000 prisoners: a systematic review of 62 surveys. Lancet 2002; 359: 545-50.

5 Wilson S, Forrester A. Too little, too late? The treatment of mentally incapacitated prisoners. J Forens Psychiatry 2002; 13: 1-8.

6 Wilson S, Dhar R. Consent to treatment, the Mental Health Act, and the Mental Capacity Act. In Psychiatry in Prisons: A Comprehensive Handbook (eds S Wilson, I Cumming): 144-54. Jessica Kingsley Publishers, 2009.

7 Forrester A, Chiu K, Dove S, Parrott J. Prison health-care wings: psychiatry's forgotten frontier? Crim Behaviour Ment Health 2010; 20: 51-61.

8 Forrester A, Henderson C, Wilson S, Cumming I, Spyrou M, Parrott J. A suitable waiting room? Hospital transfer outcomes and delays from two London prisons. Psychiatr Bull 2009; 33: 409-12.

9 United Nations. International Covenant on Economic, Social and Cultural Rights (ICESCR), Article 12. United Nations, 1976 (http:// www2.ohchr.org/english/law/pdf/cescr.pdf).

10 United Nations Committee on Economic, Social and Cultural Rights. The Right to the Highest Attainable Standard of Health: 2000-08-11. E/C.12/ 2000/4 (General Comments). Office of the United Nations High Commissioner for Human Rights, Geneva, Switzerland, 2000 (http:// www.unhchr.ch/tbs/doc.nsf/(symbol)/E.C.12.2000.4.En).

11 Her Majesty's Inspectorate of Prisons. Expectations: Criteria for Assessing the Conditions in Prisons and the Treatment of Prisoners. HMIP, 2009 (http://www.justice.gov.uk/inspectorates/hmi-prisons/docs/ expectations_2009.pdf).

12 Brooker C, Duggan S, Fox C, Mills A, Parsonage M. Short Changed: Spending On Prison Mental Health Care. Sainsbury Centre for Mental Health, 2008

13 Riviere v. France (2006) European Court of Human Rights application number 33834/03. Judgment 11 July 2006.

14 Aerts v. Belgium (2000) 29 EHRR 50. European Court of Human Rights, application number 25357/94. Judgment 30 July 1998. 